\title{
Comments to a polar bear population model
}

\author{
NILS ARE ØRITSLAND
}

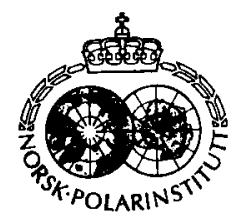

\begin{abstract}
$\emptyset$ ritsland, N. A. 1984: Comments to a polar bear population model. Polar Research 3 n.s., 123.
Larsen, T. \& Ugland, K. I. (Polar Research 2 n.s., 117-118) note correctly that a Leslie matrix model treats cubs and females as independent units which is not the case for polar bears. Population projections using the Leslie model with hunting mortalities added are instructive first approximations in evaluations of field data, however, and are recommended as exercises also for polar bear biologists. An APL programme for such projections is available.
\end{abstract}

Nils A. Øritsland, Norsk Polarinstitutt, Rolfstangveien 12, 1330 Oslo Lufthaun, Norway.

Thor Larsen and Karl I. Ugland appears to state the obvious and miss the point when commenting on our APL programme for a Leslie matrix population projection. More distressing to our vanity, however, is their final statement after having pointed out that polar bear management is a politically sensitive issue: "Scientists should therefore be extremely cautious when publishing data which are used in population projections, and make their reservations clear when data are insufficient or questionable".

Considering the major theme of our paper I suggest that the separate meaning of the terms "model" and "programme" should be kept clearly in mind. Leslie's matrix model is recommended as a useful practical population model for long lived species with a distinct seasonal breeding pattern. Our paper presented a programme, i.e. a series of instructions written in APL for a computer to execute Leslie's model and, separately, to transform age distributions directly to life table values. This is nothing more than providing a tool for carrying out textbook exercises. Further we added hunting mortalities which do not alter the characteristics of Leslie's model, but provide the user the pleasure of playing management scenarios by looking at the effects of how hunting affects population development while the natural mortalities remain unchanged. Larsen \& Ugland comment that "qualitatively, 'errors' in predictions of population development may become serious if the hunt is taking a large proportion of the females of the population" and "-that the predictions are sensitive to the input data" merely reiterate our demonstration of the computer programme. Their main criticism "-that the (Leslie) model treats cubs and females as independent units" is relevant, however, and could constructively be followed up with specific programme lines or algorithms that would expose the quantitative significance of such a modification of the model.

I now realize that we should have given more direct warnings against the commonly known pitfalls in Leslie matrix population projections than our statement: "The model accepts input fecundity and age structures blindly, i.e. it assumes that the necessary biological considerations regarding density dependencies and age structure stability are already included in the input". At the same time I strongly oppose Larsen \& Ugland's final statement. We have published a computer programme not the data used in the projections. Proper reference is made to the publication of the data and it is evident that the projections help elucidate the biological significance of the data.

Further, I suggest that polar bear biologists would benefit from now implementing simple population projection programmes as ours on the local computers and establish a set of hypothetical input parameters that can be used as a standard in comparisons of the characteristics of alternative models. Estimation procedures for input parameters belong to a field of development separate from our programme and were not within the scope of our paper. Such procedures should not be blended into the projection modules of future programme packages. It might even appear so difficult to develop sampling and estimation procedures capable of distinguishing between female and cub mortalities par se that we shall have to be content with pure Leslie matrix population projections as a first approximation for a while yet. 